\title{
Commentary: Complete surgery necessary for optimal outcome in aortic neoplasm forming malignant cartilage
}

\author{
Yoshihiko Ikeda, $\mathrm{MD}, \mathrm{PhD},{ }^{\mathrm{a}}$ and Soichiro Kitamura, $\mathrm{MD}, \mathrm{PhD}^{\mathrm{b}}$
}

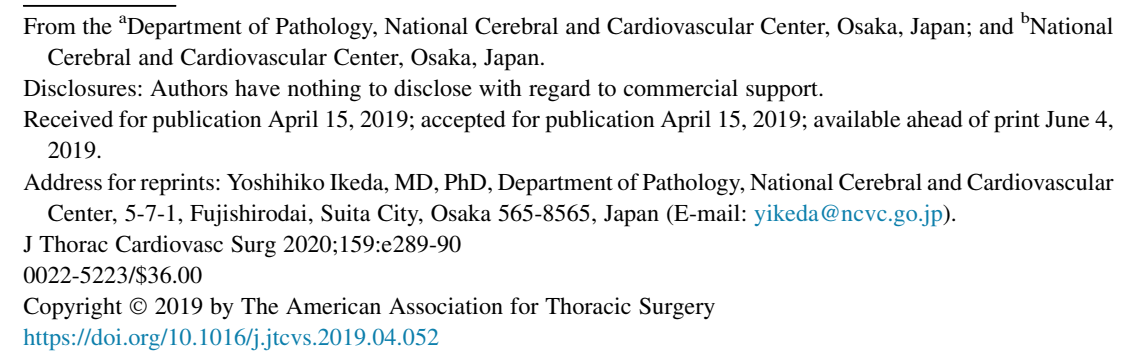

In the case reported in this issue of the Journal by Liu and colleagues, ${ }^{1}$ they show a rare case of aortic neoplasm with unique pathologic features that was surgically removed. The aortic mass (chondroma) sprouted from the posterior wall of the aorta with a small pedicle, which had been entirely resected with intima excision (endarterectomy) at the first operation. Neoformed aortic mass fully resected at the second operation was fragile and easily crushed into pieces. Neoaortic neoplasm (chondroma with increased malignancy) had invaded to the celiac artery. These findings regarding distribution and gross appearance of aortic neoplasms in the case presented by Liu and colleagues ${ }^{1}$ are suggestive of intimal sarcoma with chondrosarcomatous differentiation. Aortic intimal sarcomas are gelatinous tumors that resemble fragile thrombi (Figure 1). They are grossly confined to the lumen, with focal extension into the wall. ${ }^{2}$ Most aortic intimal sarcomas are present in the abdominal aorta, extending from the celiac artery to the iliac bifurcation. ${ }^{2-4}$ They are defined as tumors that arise in an intraluminal site with a pedicle and extend into celiac, superior mesenteric, both renal, and inferior mesenteric arteries and may show chondroid differentiation. ${ }^{5}$ The human arterial intima is composed of a small population of myofibroblastic cells, which populate the region between the internal elastic lamina and the endothelial layer and are not typically desmin-producing smooth muscle cells. ${ }^{6}$ These poorly differentiated myofibroblastic cells contain precursors that differentiate, when they become malignant, along a variety of mesenchymal lineages. It is possible that new conditions of growth at the site of recurrence favor aberrant differentiation. These include sarcoma with heterogenous elements, such as malignant bone and cartilage.

The prognosis for patients with intimal sarcoma of the aorta is generally poor. The mean overall survival is less than 16 months, ${ }^{8}$ with a 5 -year survival of $8 \% .{ }^{9}$ Primary tumors with osteoid and chondroid formation of the large

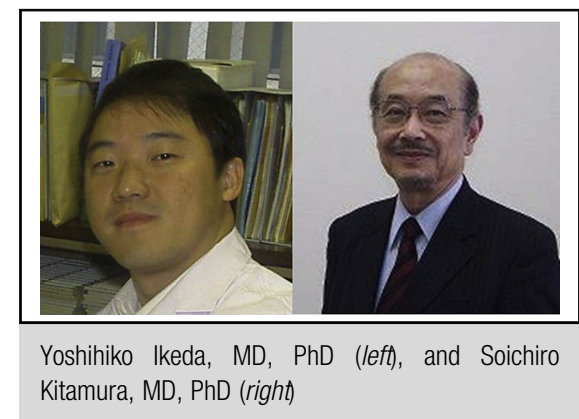

Central Message

The best treatment for a patient with aortic intimal neoplasm forming malignant cartilage is complete surgical resection with repair by synthetic graft to achieve the optimal outcome.

See Article page e287.

arteries therefore need to be considered as neoplasms with malignant nature. Simple endarterectomy may not be sufficient if there is medial infiltration by tumor. ${ }^{2}$ The roles of proton beam radiation and chemotherapy for these lesions remain to be established. In these cases, close clinical follow-up is mandatory. The postoperative follow-up period of 8 months is certainly too short to declare complete resection (full resection). It is sometime difficult but important in achieving the optimal outcome that early detection and histologic confirmation of this rare but aggressive aortic neoplasm with chondroid formation be followed by complete resection and replacement of diseased segments with

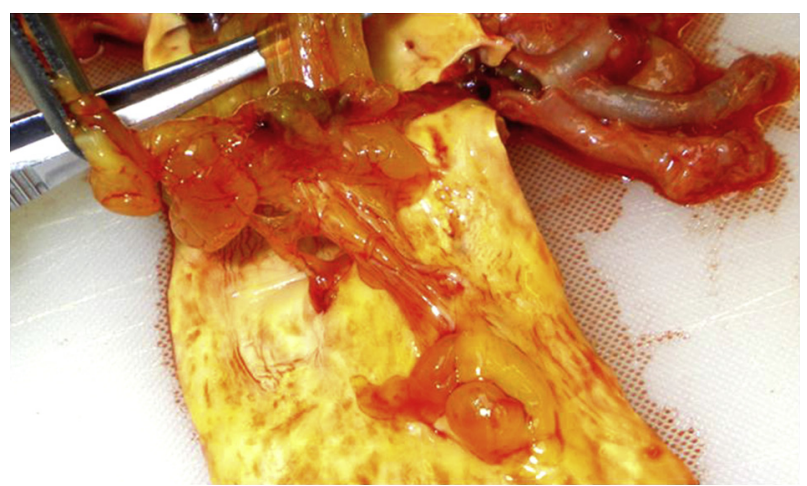

FIGURE 1. Aortic sarcoma arising in a luminal site with a pedicle and extending into celiac artery (experience at our center). 
biological or synthetic grafts. Team collaboration of cardiovascular surgeons and oncologists is also important.

\section{References}

1. Liu M, Zhang X, Li W. Primary fibroenchondroma in the descending aorta. J Thorac Cardiovasc Surg. 2020;159:e287-8.

2. Kato W, Usui A, Oshima H, Suzuki C, Kato K, Ueda Y. Primary aortic intimal sarcoma. Gen Thorac Cardiovasc Surg. 2008;56:236-8.

3. Nanjo H, Murakami M, Ebina T, Hoshi N, Sasaki T, Zhuang YJ, et al. Aortic intimal sarcoma with acute myocardial infarction. Pathol Int. 1996;46:673-81.

4. Ruijter ET, Ten Kate FJ. Metastasizing sarcoma of the aorta. Histopathology. 1996;29:278-81.
5. Burke AP, Virmani R. AFIP Atlas of Tumor Pathology. 3rd series, fascicle 16 Washington, DC: American Registry of Pathology; 1996.

6. Navarra G, Occhionorelli S, Mascoli F, Santini M, Benea G, Marzola A. Primary leiomyosarcoma of the aorta: report of a case and review of the literature. J Cardiovasc Surg (Torino). 1994;35:333-6.

7. Burke AP, Tavora FR, Maleszewski JJ, Frazier AA. AFIP Atlas of Tumor Pathology. 4th series, fascicle 22. Silver Spring (MD): American Registry of Pathology; 2015.

8. Burke AP, Virmani R. Sarcoma of the great vessels. A clinicopathologic study. Cancer. 1993;71:1761-73.

9. Chicle L, Mongredien B, Brocheriou I, Kieffer E. Primary tumors of the thoracoabdominal aorta: surgical treatment of 5 patients and review of the literature. Ann Vasc Surg. 2003;17:354-64. 